\title{
Paracorporeal right ventricular assist device for acute and chronic right heart failure in carriers of durable left ventricular assist devices
}

\author{
CDubravka Šipuš \\ OIvo Planinc, \\ BBoško Skorić, \\ OMarijan Pašalić, \\ CHrvoje Jurin, \\ -Daniel Lovrić, \\ (1) Jure Samardžić, \\ (1) Jana Ljubas Maček, \\ - $H$ Hrvoje Gašparović, \\ DBojan Biočina, \\ -Davor Miličić, \\ ○Maja Čikeš
}

University of Zagreb School of Medicine, University Hospital Centre Zagreb, Zagreb, Croatia

RECEIVED:

December 14, 2020

ACCEPTED:

December 18, 2020

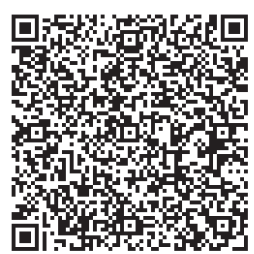

KEYWORDS: right heart failure, right ventricular assist device, ProtekDuo, left ventricular assist device. CITATION: Cardiol Croat. 2021;16(1-2):29-30. | https://doi.org/10.15836/ccar2021.29

*ADDRESS FOR CORRESPONDENCE: Dubravka Šipuš, Klinički bolnički centar Zagreb, Kišpatićeva 12, HR-10000 Zagreb, Croatia. / Phone: +385-91-7344878 / E-mail: dubravka.sipus@gmail.com

ORCID: Dubravka Šipuš, https://orcid.org/0000-0002-5631-0353 • Ivo Planinc, https://orcid.org/0000-0003-0561-6704 Boško Skorić, https://orcid.org/0000-0001-5979-2346 • Marijan Pašalić, https://orcid.org/0000-0002-3197-2190 Hrvoje Jurin, https://orcid.org/0000-0002-2599-553X • Daniel Lovrić, https://orcid.org/0000-0002-5052-6559 Jure Samardžić, https://orcid.org/0000-0002-9346-6402 • Jana Ljubas Maček, https://orcid.org/0000-0001-7171-2206 Hrvoje Gašparović, https://orcid.org/0000-0002-2492-3702 • Bojan Biočina, https://orcid.org/0000-0003-3362-9596 Davor Miličić, https://orcid.org/0000-0001-9101-1570 • Maja Čikeš, https://orcid.org/0000-0002-4772-5549

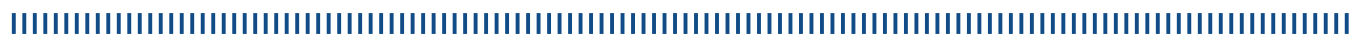

Background: Right ventricular (RV) failure is a common complication of left ventricular assist devices (LVAD). ${ }^{1,2}$ We describe two cases of durable LVAD carriers requiring acute RV mechanical support provided using the ProtekDuo (LivaNova, IT) cannula, implanted via the right jugular internal vein, bypassing the RV by draining blood from the right atrium to an extracorporeal blood pump (Rotaflow pump, Maquet, DE) and returning it to the pulmonary artery (Figure 1).

Case report 1: A 37-year-old male following LVAD implantation in 2016 due to dilated cardiomyopathy, was diagnosed with chronic RV failure in 2018. During a subsequent episode of of acute RV failure parenteral furosemide, dobutamine and intermittent levosimendan were started. Due to ensuing cardiogenic shock, veno-arterial extracorporeal membrane oxygenation (VA-ECMO) was placed. Three days later, an upgrade to a paracorporeal RVAD (p-RVAD) by placement of a ProtekDuo cannula and Rotaflow pump providing a flow of 4.15 litres/minute was performed. An improvement of hemodynamic parameters was obtained with the p-RVAD, but while awaiting the high-urgent heart transplantation, multiorgan failure and repetitive infections ensued, leading to the patients' death.

Case report 2: In April 2020, a 28-year-old male earlier diagnosed with dilated cardiomyopathy was admitted for acute heart failure. Echocardiography showed a predominant left ventricular cardiomyopathy with significantly reduced LV ejection fraction of 15\%. One week after admission, ventricular fibrillation occurred, terminated by implantable cardioverter-defibrillator. Due to hemodynamic com-

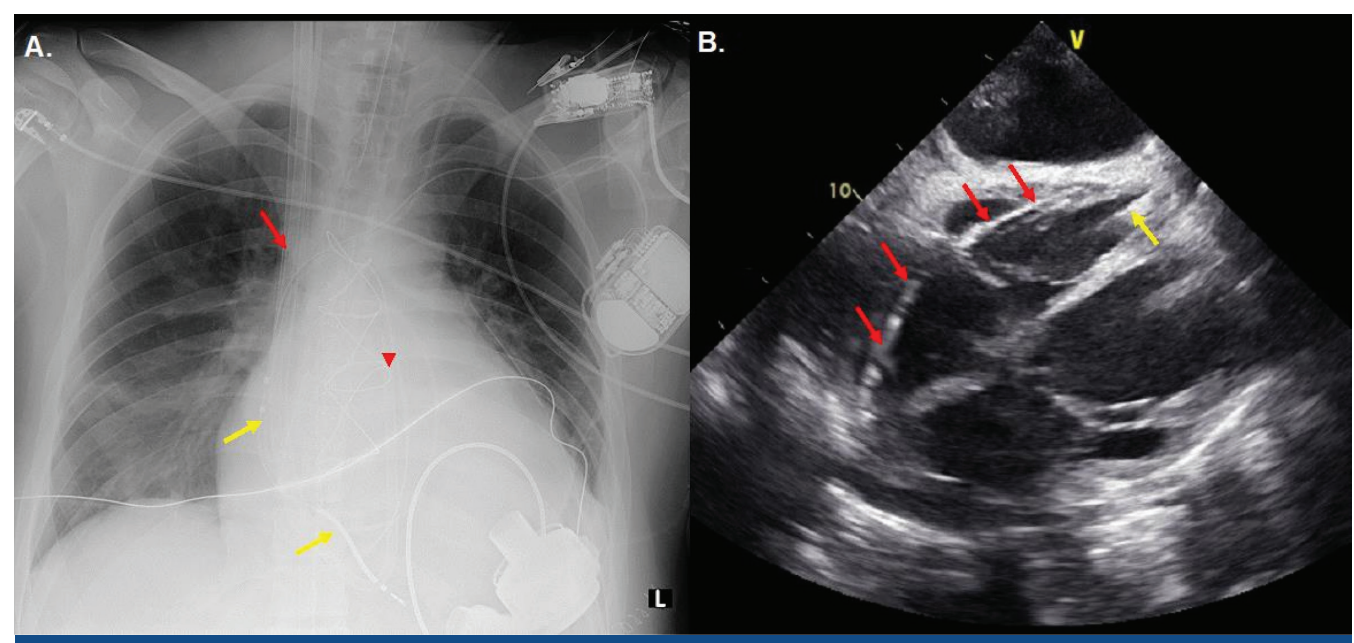

FIGURE 1. A) Chest X-ray after HM3 and ProtekDuo placement. B) Transthoracal echocardiography subcostal 4-chamber view. Red arrows indicate ProtekDuo cannula, red arrowhead indicates the tip of the cannula in the pulmonary artery. Yellow arrows indicate implantable-cardioverter defibrillator electrode. 
promise, dobutamine and norepinephrine were started, but VA-ECMO was required soon thereafter. Three days later, a durable LVAD (HeartMate 3, Abbott, USA) implantation was performed, however the patient was not weanable from cardiopulmonary bypass due to acute RV failure, and promptly received a p-RVAD with the ProtekDuo cannula. Two weeks later, the p-RVAD was successfully weaned and he was discharged a month later and is currently in regular follow-up.

Conclusion: We present two cases of acute and chronic RV failure in LVAD carriers. In both cases, the ProtekDuo cannula enabled acute RV support. Early institution of RV mechanical circulatory support, when needed, should improve patient outcomes. CardiacAssist Protek-Duo TandemHeart to Preempt Right Heart Failure. Med Sci Monit Basic Res. 2016 May 5:22:53-7. https://doi.org/10.12659/MSMBR.898897

2. Schmack B, Farag M, Kremer J, Grossekettler L, Brcic A, Raake PW, et al. Results of concomitant groin-free percutaneous temporary RVAD support using a centrifugal pump with a double-lumen jugular venous cannula in LVAD patients. J Thorac Dis. 2019 Apr;11(Suppl 6):S913-S920. https://doi.org/10.21037/jtd.2018.11.121 